\title{
PROFILE OF SURROGATE MARKERS OF MOLECULAR SUBTYPES USING THE EXPRESSION PATTERN OF ER, PR, AND HER2/NEU RECEPTORS IN OPERABLE BREAST CANCER
}

\author{
VISHAL VERMA ${ }^{1 *}$, HIREMATH RN ${ }^{2}$, SHARANJIT SINGH BASRA ${ }^{3}$, NIRAJ CHOUREY ${ }^{4}$, POOJA SINHA ${ }^{5}$
}

${ }^{1}$ Surgical specialist, New Delhi, India. ${ }^{2}$ Public Health Specialist, Bengaluru, India. ${ }^{3}$ Surgical specialist, Amritsar, Punjab, India. ${ }^{4}$ Gynecologist, Babina, Uttar Pradesh, India, ${ }^{5}$ Department of Obstetrics and Gynecologist, Pandit Bhagwat Dayal Sharma Post Graduate Institute of Medical Sciences, Rohtak, Haryana, India. Email: wishmamc@yahoo.com

Received: 20 June 2021, Revised and Accepted: 18 August 2021

ABSTRACT

Objective: The present study was planned with an aim to study the profile of surrogate markers of molecular subtypes using the expression pattern of ER, PR, and HER2/NEU receptors in operable breast cancer so that most effective and advantageous treatment can be offered for better surgical outcomes.

Methods: A cross-sectional observational study was carried out in one of the tertiary care centers in Central UP. All patients presenting to the center with early and locally advanced breast cancer with age bracket between 18 and 75 years during 2-year period and willing to participate in the study were included in the sample size. Clinical staging was done using the standard TNM criteria and all the specimens were subjected to immunohistochemical evaluation for surrogate molecular subtyping

Results: Out of 94 cases enrolled in the study, a total of 32 (34.4\%) were identified as luminal A, 3 (3.2\%) were identified as luminal B, 35 (37.6\%) were identified as HER2 positive, and remaining 23 (24.7\%) were identified as triple negative. Statistically, there was no significant difference among groups with respect to age $(\mathrm{p}=0.958)$ and BMI $(\mathrm{p}=0.332)$. However, there was a significant difference among groups with respect to clinical stage $(\mathrm{p}=0.031)$, clinical nodal involvement $(\mathrm{p}=0.014)$, pathological staging $(\mathrm{p}=0.006)$, and pathological nodal involvement ( $\mathrm{p}=0.023)$. Among those with nodal involvement, all the cases had involvement of one node except for one patient in Group I who had involvement of thrMost of the luminal A cases (81.3\%) were clinically Stage 1 or 2. All the luminal B cases were clinically Stage 2 or 3 (100\%). Almost half (48.8\%) of Her2-negative cases were Stage 3 or 4. Majority of triple-negative cases were Stage 3 or 4 (65.2\%). Clinically, nodal involvement was seen to be maximum in Her2-negative and triple-negative groups (54.3\% and $52.2 \%$ of cases, respectively). Pathologically, most of the luminal A (83.9\%), Her2 negative (81.8\%), and all the luminal B cases were Stage 2. Pathologically, nodal involvement was seen in $16.1 \%$ of luminal A, $42.4 \%$ of Her2-negative, and $50 \%$ of triple-negative cases.

Conclusion: The findings of the present study provided a glimpse of expression pattern of ER, PR, and HER2/NEU receptors in operable breast cancer based on which most effective and advantageous treatment can be offered for better surgical outcomes.

Keywords: Surrogate markers, Molecular subtypes, Breast cancer.

(c) 2021 The Authors. Published by Innovare Academic Sciences Pvt Ltd. This is an open access article under the CC BY license (http://creativecommons.org/ licenses/by/4.0/) DOI: http://dx.doi.org/10.22159/ajpcr.2021v14i9.42526. Journal homepage: https://innovareacademics.in/journals/index.php/ajpcr

\section{INTRODUCTION}

Cancer of the breast in women is a major health burden worldwide. It is the most common cause of cancer among women in both highresource and low-resource settings and is responsible for over 1 million of the estimated 10 million neoplasms diagnosed worldwide each year in both sexes. It is also the primary cause of cancer death among women globally, responsible for about 375,000 deaths in the year 2000 [1]. While most breast cancer patients in western countries are postmenopausal and in their $60 \mathrm{~s}$ and $70 \mathrm{~s}$, the picture is quite different in India with premenopausal patients constituting about $50 \%$ of all patients [2].

Although in recent years, with the improvement in management techniques, the 5-year mortality rate has been brought down to lesser than $10 \%$ as compared to nearly $25 \%$ during the 1970 s [3]. This improvement in survival statistics is generally attributable to abundant use of mammographic screening and improved systemic treatment, primarily adjuvant endocrine therapy. However, evidence is gathering that survival improvements differ by breast cancer subtypes defined by hormone receptor status, with the greatest improvements observed for estrogen receptor-positive cancers.

Estrogen receptor (ER) and progesterone receptor (PR) expression jointly define distinct phenotypic and molecular characteristics and also provide information about the natural history and sensitivity to adjuvant hormonal therapies observed across tumor subtypes. There are studies that have evaluated time trends in stage-specific breast cancer survival rates according to joint ER/PR status along with some other molecular markers like HER2/NEU18 [4]. It has been shown that these parameters together might have the ability to further help in identifying treatment gaps where progress could be made to increase the treatment outcome. It has been shown that screening helps to identify early stage breast cancer, however, hormonal therapy is useful only to those with hormone receptor-positive disease.

With the recognition and acceptance of the heterogeneity of breast cancer, there is an increasing emphasis on understanding it with wider perspective that includes a wide spectrum of clinical, pathologic, and molecular features. With the increasing knowledge, molecular classification is being widely accepted as it helps in a holistic characterization of breast cancer and also helps in generating gene profiling models which help in predicting outcomes [5]. However, despite this knowledge, the clinicians generally emphasize on traditional clinicopathologic features and tumor markers such as estrogen receptor (ER), progesterone receptor (PR), and human epidermal growth factor receptor 2 (HER2), for their ease of availability.

ER, PR, and HER2 assessments can be done in routine, are relatively cheap, reliable, and helpful in therapeutic decision-making. There is 
ample evidence available from population-based studies that these techniques are reasonable substitutes for the more expensive molecular subtyping. A total of eight combinations of ER, PR, and HER2 can be made out and there are reports that indicate that combinations have a significant variability in the demographics, tumor characteristics, and survival, thus making them a suitable alternative for assessing and predicting the outcome.

With this background, the present study was planned with an aim to study the profile of surrogate markers of molecular subtypes using the expression pattern of ER, PR, and HER2/NEU receptors in operable breast cancer so that most effective and advantageous treatment can be offered for better surgical outcomes.

\section{METHODS}

A cross-sectional observational study was carried out in one of the tertiary care centers in Central UP. All patients presenting to the center with early and locally advanced breast cancer with age bracket between 18 and 75 years during 2-year period and willing to participate in the study were included in the sample size. Cases with patients with metastatic cancer, inoperable tumor, and who are medically unfit were excluded from the study. After obtaining informed consent from the patients, diagnostic confirmation to rule out any exclusion criteria was performed. Patient's age, gender, and duration of disease were noted. Anthropometric measurements were taken, and BMI was calculated. Clinical staging was done using the standard TNM criteria. All the specimens were subjected to immunohistochemical evaluation for surrogate molecular subtyping using the following criteria:

Luminal A ER+/PR+/HER2-, ER+/PR-/HER2-, ER-/PR+/HER2Luminal B ER+/PR+/HER2+, ER+/PR-/HER2+, and ER-/PR+/HER2+ $\mathrm{HER} /$ neu+ $\quad$ ER-/PR-/HER2+

Triple negative ER-/PR-/HER2-

Data were entered into Excel sheet and statistical analysis was done using Statistical Package for the Social Sciences version 15.0 or above.

\section{RESULTS}

Out of 94 cases enrolled in the study, a total of 32 (34.4\%) were identified as luminal A, $3(3.2 \%)$ were identified as luminal B, $35(37.6 \%)$ were identified as HER2 positive, and remaining 23 (24.7\%) were identified as triple negative (Table 1). Age of patients ranged from 26 to 75 years. Mean age of patients in different groups ranged from $47.57 \pm 9.57$ (Group III) to $50.67 \pm 8.08$ (Group II) years. Statistically, there was no significant difference among groups with respect to age $(p=0.958)$. All the patients were female. BMI of patients ranged from 18.25 to $33.78 \mathrm{~kg} / \mathrm{m}^{2}$. Mean BMI in different groups ranged from 23.71 (Group IV) to $26.38 \mathrm{~kg} / \mathrm{m}^{2}$ (Group II), however, the difference among groups was not significant statistically $(p=0.332)$ (Table 2$)$

In Group I, a total of 4 (12.5\%) were Stage T1, 22 (68.8\%) were Stage T2, $4(12.5 \%)$ were Stage T3, and 2 (6.2\%) were Stage T4. In Group II, $2(66.7 \%)$ were T2 and $1(33.3 \%)$ was T3. In Group III, $18(51.4 \%)$ were $\mathrm{T} 2,14(40 \%)$ were stage $\mathrm{T} 3$, and remaining $3(8.6 \%)$ were $\mathrm{T} 4$. In Group IV, 7 (30.4\%) were T2, $12(52.2 \%)$ were T3, $3(13 \%)$ were $\mathrm{T} 4$, and remaining $1(4.3 \%)$ was Tx. Statistically, there was a significant difference among groups with respect to clinical stage $(p=0.031)$.

Clinical nodal involvement was seen in $21.9 \%$ of Group I (6 N1, 1 N3), 54.3\% of Group III (all N1), and 52.2\% of Group IV (all N1) cases. None of the cases in Group II had nodal involvement. Statistically, there was a significant difference among groups with respect to nodal involvement $(\mathrm{p}=0.014)$

\section{Table 1: Distribution of cases according to molecular profile}

\begin{tabular}{lllll}
\hline S. No. & Group & Molecular profile & No. of cases & Percentage \\
\hline 1. & I & Luminal A & 32 & 34.4 \\
2. & II & Luminal B & 3 & 3.2 \\
3. & III & HER2 positive & 35 & 37.6 \\
4. & IV & Triple negative & 23 & 24.7
\end{tabular}

After the surgery, the pathological staging of cases was ascertained. Table 3 shows the pathological staging of cases. Pathological stage could be determined in 89 cases. There was one case each in Group I and Group III and two cases in Group III, in whom pathological stage could not be determined. In Group I, a total of $3(9.7 \%)$ were pathologically Stage I, $26(83.9 \%)$ were Stage 2, and $2(6.5 \%)$ were Stage 2 . All the cases in Group II were pathologically Stage 2. In Group III, a total of $27(81.8 \%)$ were Stage 2 and remaining $6(18.2 \%)$ were Stage 3. In Group IV, 11 (50\%) were Stage 2, 9 (40.9\%) were Stage 3, and remaining $2(9.1 \%)$ were Stage 4 . Statistically, there was a significant difference among groups with respect to pathological staging $(\mathrm{p}=0.006)$.

Pathological nodal involvement was seen in $16.1 \%$ of Group I (4 PN1, 1 PN3), $42.4 \%$ of Group III (13 PN1, 1 PN2), and 50\% of Group IV (9 PN1, 1 PN2, 1 PN3) cases. In Group II, none of the three cases had nodal involvement. Statistically, there was a significant difference among groups with respect to nodal involvement $(\mathrm{p}=0.023)$. Among those with nodal involvement, all the cases had involvement of one node except for one patient in Group I and two patients in Group II. Her-2-positive subtype (Group III) was most common (37.6\%) followed by luminal A (Group I) (34.4\%) and triple negative (Group IV) (24.7\%). Luminal B subtype (Group II) was least common (3.2\%).

\section{DISCUSSION}

With the increasing awareness regarding breast cancer and increased access to diagnostic modalities, the prevalence of breast cancer is

Table 2: Comparison of mean age and BMI of patients with different molecular profile

\begin{tabular}{lllllll}
\hline S. No. & Group & $\begin{array}{l}\text { No. of } \\
\text { cases }\end{array}$ & Mean age & SD & Range & p value \\
\hline 1. & I & 32 & 48.38 & 11.96 & $31-75$ & $\mathrm{p}=0.958$ \\
2. & II & 3 & 50.67 & 8.08 & $42-58$ & \\
3. & III & 35 & 47.57 & 9.57 & $30-70$ & \\
4. & IV & 23 & 48.09 & 8.03 & $26-59$ & \\
& Total & 93 & 48.08 & 9.96 & $26-75$ & \\
\hline S. No. & Group & No. of & Mean BMI & SD & Range & p value \\
& & cases & & & & \\
\hline 1. & I & 32 & 24.16 & 3.29 & $18.3-32.08$ & $\mathrm{p}=0.332$ \\
2. & II & 3 & 26.38 & 2.24 & $24.03-28.5$ & \\
3. & III & 35 & 25.23 & 3.98 & $18.65-33.78$ & \\
4. & IV & 23 & 23.71 & 3.91 & $18.25-32.04$ & \\
& Total & 93 & 24.52 & 3.71 & $18.25-33.78$ & \\
\hline
\end{tabular}

Table 3: Comparison of clinical stage, clinical nodal status, and pathological nodal status of tumor in different molecular profiles

\begin{tabular}{|c|c|c|c|c|c|c|c|c|c|c|}
\hline \multirow{2}{*}{\multicolumn{2}{|c|}{ No. }} & \multicolumn{2}{|c|}{$\begin{array}{l}\text { Group I } \\
(n=32)\end{array}$} & \multicolumn{2}{|c|}{$\begin{array}{l}\text { Group II } \\
(n=3)\end{array}$} & \multicolumn{2}{|c|}{$\begin{array}{l}\text { Group III } \\
(n=35)\end{array}$} & \multicolumn{2}{|c|}{$\begin{array}{l}\text { Group IV } \\
(n=23)\end{array}$} & \multirow[t]{2}{*}{$p$ value } \\
\hline & & $\%$ & No. & $\%$ & No. & $\%$ & No. & $\%$ & & \\
\hline \multicolumn{11}{|c|}{ Clinical stage } \\
\hline 1. & $\mathrm{~T} 1$ & 4 & 12.5 & 0 & 0 & 0 & 0 & 0 & 0 & $\mathrm{p}=0.031$ \\
\hline 2. & $\mathrm{~T} 2$ & 22 & 68.8 & 2 & 66.7 & 18 & 51.4 & 7 & 30.4 & \\
\hline 3. & T3 & 4 & 12.5 & 1 & 33.3 & 14 & 40.0 & 12 & 52.2 & \\
\hline 4. & $\mathrm{~T} 4$ & 2 & 6.2 & 0 & 0 & 3 & 8.6 & 3 & 13.0 & \\
\hline 5. & $\mathrm{Tx}$ & 0 & 0 & 0 & 0 & 0 & 0 & 1 & 4.3 & \\
\hline \multicolumn{11}{|c|}{ Clinical nodal status } \\
\hline 1. & N0 & 25 & 78.1 & 3 & 100.0 & 16 & 45.7 & 11 & 47.8 & $\mathrm{p}=0.014$ \\
\hline 2. & $\mathrm{~N} 1$ & 6 & 18.6 & 0 & 0.0 & 19 & 54.3 & 12 & 52.2 & \\
\hline 3. & $\mathrm{~N} 2$ & 0 & 0 & 0 & 0 & 0 & 0 & 0 & 0 & \\
\hline & N3 & 1 & 3.1 & 0 & 0 & 0 & 0 & 0 & 0 & \\
\hline \multicolumn{11}{|c|}{ Pathological nodal status } \\
\hline 1. & PNO & 26 & 83.9 & 3 & 100.0 & 19 & 57.6 & 11 & 50.0 & $\mathrm{p}=0.006$ \\
\hline 2. & PN1 & 4 & 12.9 & 0 & 0.0 & 13 & 39.4 & 9 & 40.9 & \\
\hline 3. & PN2 & 0 & 0 & 0 & 0.0 & 1 & 3.0 & 1 & 4.5 & \\
\hline 4. & PN3 & 1 & 3.2 & 0 & 0 & 0 & 0.0 & 1 & 4.5 & \\
\hline
\end{tabular}


increasing. With increasing clinicopathological correlations, the prognosis of breast cancer is improving. However, attempts are still being made to understand various clinicopathological, physiological, and biochemical variables affecting the outcome and prognosis in breast cancer cases. In the recent years, molecular subtyping of breast cancer is used as an improvised tool to help in understanding the underlying mechanisms and genetic predisposition that might affect the extent and outcome of breast cancer. In the present study, we made an attempt to study the profile of surrogate markers of molecular subtypes using the expression pattern of ER, PR, and HER2/NEU receptors in operable breast cancer so that most effective and advantageous treatment can be offered for better surgical outcomes.

In the human mammary gland, two cell types are distinguished immunohistochemically; the basal (and/or myoepithelial) cells can be stained with the antibodies against keratin 5/6, whereas the luminal epithelial cells can be stained with the antibodies against keratin 8/1 [6]. The luminal cells may be positive or negative for ER, PR and Her-2/ neu.

The ER-positive/luminal tumors can be grouped into two subtypes, luminal A and luminal B. The luminal A tumors demonstrate the highest expression of the ER and the ER-related genes and they show the best prognosis. The luminal B tumors have profiles which are enriched for the "luminal genes," but they show a low to moderate expression of the genes which pertain to the ER cluster. As compared to the luminal A tumors, they may have a higher proliferation rate, they may express genes that seem to be shared with the basal-like and the Her-2 subtypes and they are associated with a less favorable outcome [7]. In the present study, we also made an attempt to find out association of this molecular subtyping pattern using ER/PR and Her-2 expression as the indicators of different molecular subtypes based on luminal classification. The subtype definitions used for the purpose of study were as follows: Luminal A (ER+ and/or progesterone receptor (PR) +, Her-2/neu-) (Group I), luminal B (ER+ and/or PR+, HER2+) (Group II), Her-2/neu positive (ER-/PR-, Her-2/neu+) (Group III), and triple negative (ER-, PR-, Her2-) (Group IV).

For this purpose, a total of 94 cases falling in sampling frame were enrolled in the study. Based on above classification, Her-2-positive subtype (Group III) was most common (37.6\%) followed by luminal A (Group I) (34.4\%) and triple negative (Group IV) (24.7\%). Luminal B subtype (Group II) was least common (3.2\%). The prevalence of various subtypes as reported in different case series is as follows.

An overview of Table 4 shows that the prevalence of different molecular subtypes varies substantially in different studies. In the present study, majority of patients were Her-2/neu positive, however, most of the other studies indicate luminal A to be the most common type. However, there are exceptions too, like Maisonneuve et al. (2014) [14] who observed luminal B type to be more common than luminal A. However, we do not claim that luminal A to be most common type in general but limit the findings to the present work only. It is known that luminal A type is generally associated with low-grade cancers, however, where chemotherapy is often suggested as the viable treatment option either alone or as an adjuvant therapy. However, in the present study, majority of patients have not received chemotherapy. However, despite this difference, the proportion of luminal A subtype was only marginally lower as compared to the most dominant subtype (Her2/neu positive) in the present study. These findings indicate that proportion of patients with different molecular subtypes might be dependent on a host of factors including the purpose of study, design of study, sample size, definition criteria, and patient characteristics.

In the present study, the age of patients ranged from 26 to 75 years with a mean age of $48.08 \pm 9.96$ years. In few reports [8,19], an association between age and luminal subtypes has been reported with triple negative type to be more common in younger age groups. However, in the present study, no such effect of age was reflected across different molecular subtypes in the present study. As a matter of fact, patients below $<35$ years and $<40$ years of age comprised only a fractional portion of entire study population $(12.8 \%$ and $16.0 \%$, respectively). As far as range of age is concerned, despite being in low percentages, it is disappointing to see that people at younger ages are being affected by breast cancer, however, this is not an unusual finding. In the present study, minimum age of a patient was 26 years but there are reports that have included patients much younger than this [10]. Contrary to findings of the present study, Park et al. (2013) [20] made a point that ER+/PR- patients had the oldest age at diagnosis, and ER-/PR+ was associated with the youngest age at onset and Grade III tumor. Ugras et al. (2014) [15] also showed an association between age and molecular subtypes. However, in the present study, though we observed mean age of patients with luminal B subtype to be maximum, yet we could not deduce any significant association of age with luminal subtype. As far as mean age of patients is concerned, the findings of the present study coincide with the observations of various recent Indian studies in literature that have cited mean age of patients to be close to 50 years $[18,21,22]$. In the present study, no association between BMI and molecular subtyping could be observed. BMI of patients ranged from 18.25 to $33.78 \mathrm{~kg} / \mathrm{m}^{2}$ with a mean of $24.52 \pm 3.71 \mathrm{~kg} / \mathrm{m}^{2}$. A large proportion of patients was overweight and obese (BMI>25.0 kg/m $\mathrm{m}^{2}$ ) (41.5\%). On reviewing the literature, we did not encounter any study indicating association between BMI and molecular subtyping. In the recent years, more and more evidence is supported showing association between obesity and breast cancer [23] and the high prevalence of overweight and obese patients in the present study substantiated this relationship.

In the present study, luminal A and luminal B subtypes were found to be associated with lower clinical grades while Her2/neu-positive and triple-negative subtypes had significantly higher proportion of patients with higher clinical grades. Similarly, nodal involvement was significantly more common in Her2/neu-positive and triplenegative subtypes. This finding is in agreement with a plenty of reports in literature [15,17-18,20-22]. On evaluating the association of pathological grade and nodal involvement levels too, the clinical

Table 4: Prevalence of various molecular subtypes among carcinoma breast patients in different case series

\begin{tabular}{|c|c|c|c|c|c|c|}
\hline S. No. & Author (year) & Sample size & Luminal A (\%) & Luminal B (\%) & Her2 +ve (\%) & Triple negative/basal cell type (\%) \\
\hline 1. & Ihemelandu et al. (2007) [8] & - & 55.4 & 11.8 & 11.6 & 21.2 \\
\hline 2. & Cheang et al. (2010) [9] & 357 & 59 & 33 & - & 9 \\
\hline 3. & Li et al. (2011) [10] & 316 & 33.2 & 11.7 & 26.3 & 28.8 \\
\hline 4. & Caudle et al. (2012) [11] & 595 & 51.9 & 8.6 & 7.1 & 32.4 \\
\hline 5. & Dominici et al. (2012) [12] & 819 & 70 & 7 & 6.2 & 11.5 \\
\hline 6. & Joensuu et al. (2013) [13] & 72 & 48.6 & 5.6 & 11.1 & 14.0 \\
\hline 7. & Maisonneuve et al. (2014) [14] & 9415 & 33.7 & 66.3 & - & - \\
\hline 9. & Kumar De et al. (2015) [16] & 23 & 39.1 & 13.0 & 13.0 & 34.8 \\
\hline 10. & Kumar et al. (2015) [17] & 56 & 33.9 & 17.9 & 17.9 & 26.8 \\
\hline 11. & Alnegheimish et al. (2016) [18] & 359 & 58.5 & 14.5 & 12.3 & 14.8 \\
\hline 12. & Present study & 94 & 34.4 & 3.2 & 37.6 & 24.7 \\
\hline
\end{tabular}


findings correlated substantially with the clinical findings and thus endorsed the observations made by the previous studies.

\section{CONCLUSION}

Most of the luminal A cases (81.3\%) were clinically Stage 1 or 2 . All the luminal B cases were clinically Stage 2 or 3 (100\%). Almost half (48.8\%) of Her2-negative cases were Stage 3 or 4 . Majority of triple-negative cases were Stage 3 or 4 (65.2\%). Clinically, nodal involvement was seen to be maximum in Her2-negative and triple-negative groups $(54.3 \%$ and $52.2 \%$ of cases, respectively). Pathologically, most of the luminal A (83.9\%), Her2 negative (81.8\%), and all the luminal B cases were Stage 2. Pathologically, nodal involvement was seen in $16.1 \%$ of luminal A, $42.4 \%$ of Her2-negative, and $50 \%$ of triple-negative cases. The findings of the present study provided a glimpse of expression pattern of ER, PR, and HER2/NEU receptors in operable breast cancer based on which most effective and advantageous treatment can be offered for better surgical outcomes.

\section{ACKNOWLEDGMENTS}

I acknowledge and thank to all my coauthors, and study participants.

\section{AUTHORS' CONTRIBUTIONS}

All authors have contributed to the preparation of manuscript.

\section{CONFLICTS OF INTEREST}

Nil.

\section{AUTHORS' FUNDING}

Nil.

\section{REFERENCES}

1. Parkin DM, Bray F, Ferlay J, Pisani P. Estimating the world cancer burden: Globocan 2000. Int J Cancer 2001;94:153-6.

2. Igene H. Global health inequalities and breast cancer: An impending public health problem for developing countries. Breast J 2008;14:428-34.

3. Howlader N, Altekruse SF, Li CI, Chen VW, Clarke CA, Ries LA, et al. US incidence of breast cancer subtypes defined by joint hormone receptor and HER2 status. J Natl Cancer Inst 2014;106:dju055.

4. Wang C, Tran DA, Fu MZ, Chen W, Fu SW, Li X. Estrogen receptor, progesterone receptor, and HER2 receptor markers in endometrial cancer. J Cancer 2020;11:1693-701.

5. Malone ER, Oliva M, Sabatini PJ, Stockley TL, Siu LL. Molecular profiling for precision cancer therapies. Genome Med 2020;12:8.

6. Carey LA, Perou CM, Livasy CA, Dressler LG, Cowan D, Conway K, et al. Race, breast cancer subtypes, and survival in the Carolina breast cancer study. J Am Med Assoc 2006;295:2492-502.

7. Ma XJ, Wang Z, Ryan PD, Isakoff SJ, Barmettler A, Fuller A, et al. A two-gene expression ratio predicts clinical outcome in breast cancer patients treated with tamoxifen. Cancer Cell 2004;5:607-16.
8. Tamimi RM, Baer HJ, Marotti J, Galan M, Galaburda L, Fu Y, et al. Comparison of molecular phenotypes of ductal carcinoma in situ and invasive breast cancer. Breast Cancer Res 2008;10:R67.

9. Caudle AS, Yu TK, Tucker SL, Bedrosian I, Litton JK, Gonzalez Angulo AM, et al. Local-regional control according to surrogate markers of breast cancer subtypes and response to neoadjuvant chemotherapy in breast cancer patients undergoing breast conserving therapy. Breast Cancer Res 2012;14:R83.

10. Dominici LS, Mittendorf EA, Wang X, Liu J, Kuerer HM, Hunt KK, et al. Implications of constructed biologic subtype and its relationship to locoregional recurrence following mastectomy. Breast Cancer Res 2012;14:R82.

11. Rattan B, Manjari M, Kahlon SK, Kalra N, Bhalla A, Paul S. The immunohistochemical expression of the oestrogen receptor (ER), HER-2/NEU and cytokeratin 8/18 and 5/6 in invasive breast carcinoma. J Clin Diagn Res 2012;6:1495-8.

12. Margalit DN, Sreedhara M, Chen YH, Catalano PJ, Nguyen PL, Golshan M, et al. Microinvasive breast cancer: ER, PR, and HER-2/ neu status and clinical outcomes after breast-conserving therapy or mastectomy. Ann Surg Oncol 2013;20:811-8.

13. Purdie CA, Quinlan P, Jordan LB, Ashfield A, Ogston S, Dewar JA, et al. Progesterone receptor expression is an independent prognostic variable in early breast cancer: A population-based study. Br J Cancer 2014;110:565-72.

14. Li A, Zhou S, Li M, Xu Y, Shui RH, Yu BH, et al. Clinicopathologic characteristics of oestrogen receptor-positive/progesterone receptornegative/her2-negative breast cancer according to a novel definition of negative progesterone receptor status: A large population-based study from China. PLoS One 2015;10:e0125067.

15. Kumar De S, Shashikala P, Pruthvi D, Kavita GU, Nandyal SN, Shwetha JH. Estrogen, progesterone and human epidermal growth factor receptor-2 in malignant breast lesions: A 5 year study in a tertiary care hospital of Karnataka. India J Pathol Oncol 2015;2:230-5.

16. Harbeck N, Jakesz R. St. Gallen 2007: Breast cancer treatment consensus report. Breast Care 2007;2:130-4.

17. Alnegheimish NA, Alshatwi RA, Alhefdhi RM, Arafah MM, AlRikabi AC, Husain S. Molecular subtypes of breast carcinoma in Saudi Arabia. Saudi Med J 2016;37:506-12.

18. Stephenson GD, Rose DP. Breast cancer and obesity: An update. Nutr Cancer 2003;45:1-16.

19. Onitilo AA, Engel JM, Greenlee RT, Mukesh BN. Breast cancer subtypes based on ER/PR and her2 expression: Comparison of clinicopathologic features and survival. Clin Med Res 2009;7:4-13.

20. Maisonneuve P, Disalvatore D, Rotmensz N, Curigliano G, Colleoni M, Dellapasqua $\mathrm{S}$, et al. Proposed new clinicopathological surrogate definitions of luminal A and luminal B (HER2-negative) intrinsic breast cancer subtypes. Breast Cancer Res 2014;16:R65.

21. Cherbal F, Gaceb H, Mehemmai C, Saiah I, Bakour R, Rouis AO, et al. Distribution of molecular breast cancer subtypes among Algerian women and correlation with clinical and tumor characteristics: A populationbased study. Breast Dis 2015;35:95-102.

22. Kumar N, Patni P, Agarwal A, Khan MA, Parashar N. Prevalence of molecular subtypes of invasive breast cancer: A retrospective study. MJAFI 2015;71:254-8

23. Ligibel J. Obesity and breast cancer. Oncology (Williston Park) 2011;25:994-100056. 